\title{
Relative contributions of testosterone and estrogen in regulating bone resorption and formation in normal elderly men
}

\author{
Alireza Falahati-Nini, ${ }^{1}$ B. Lawrence Riggs, ${ }^{1}$ Elizabeth J. Atkinson, ${ }^{2}$ \\ W. Michael O'Fallon, ${ }^{2}$ Richard Eastell, ${ }^{3}$ and Sundeep Khosla ${ }^{1}$ \\ ${ }^{1}$ Endocrine Research Unit, and \\ ${ }^{2}$ Department of Biostatistics, Mayo Clinic and Mayo Foundation, Rochester, Minnesota, USA \\ ${ }^{3}$ Division of Clinical Sciences, Northern General Hospital, Sheffield, United Kingdom \\ Address correspondence to: Sundeep Khosla, Mayo Clinic, 200 First Street SW, 5-164 West Joseph, \\ Rochester, Minnesota 55905, USA. Phone: (507) 255-6788; Fax: (507) 255-4828; E-mail: khosla.sundeep@mayo.edu.
}

Received for publication August 3, 2000, and accepted in revised form November 6, 2000.

Young adult males who cannot produce or respond to estrogen (E) are osteopenic, suggesting that E may regulate bone turnover in men, as well as in women. Both bioavailable $\mathrm{E}$ and testosterone $(\mathrm{T})$ decrease substantially in aging men, but it is unclear which deficiency is the more important factor contributing to the increased bone resorption and impaired bone formation that leads to their bone loss. Thus, we addressed this issue directly by eliminating endogenous $\mathrm{T}$ and $\mathrm{E}$ production in 59 elderly men (mean age 68 years), studying them first under conditions of physiologic $\mathrm{T}$ and $\mathrm{E}$ replacement and then assessing the impact on bone turnover of withdrawing both $\mathrm{T}$ and $\mathrm{E}$, withdrawing only $\mathrm{T}$, or only $\mathrm{E}$, or continuing both. Bone resorption markers increased significantly in the absence of both hormones and were unchanged in men receiving both hormones. By two-factor ANOVA, E played the major role in preventing the increase in the bone resorption markers, whereas $\mathrm{T}$ had no significant effect. By contrast, serum osteocalcin, a bone formation marker, decreased in the absence of both hormones, and both $\mathrm{E}$ and $\mathrm{T}$ maintained osteocalcin levels. We conclude that in aging men, $\mathrm{E}$ is the dominant sex steroid regulating bone resorption, whereas both $\mathrm{E}$ and $\mathrm{T}$ are important in maintaining bone formation.

J. Clin. Invest. 106:1553-1560 (2000).

\section{Introduction}

While the role of estrogen (E) in regulating bone metabolism in women is well established, the relative contributions of $\mathrm{E}$ versus testosterone $(\mathrm{T})$ in regulating bone turnover in men remain unclear. Since $\mathrm{T}$ is the dominant sex steroid secreted in men, the traditional belief has been that $\mathrm{E}$ is the major sex steroid regulating bone metabolism in women and $\mathrm{T}$ is the major sex steroid regulating bone metabolism in men. This concept has been challenged, however, by the description of several "experiments of nature." A male carrying homozygous mutations in the $\mathrm{E}$ receptor- $\alpha(E R-\alpha)$ gene (who was unable to respond to E) (1) and two males with homozygous mutations in the aromatase gene (who were unable to synthesize E) (2-4) had osteopenia, unfused epiphyses, and elevated indices of bone turnover. Moreover, E therapy in the two aromatasedeficient males corrected these abnormalities (3-5).

These reports have led to a reconsideration of the possible role of $\mathrm{E}$ in regulating the male skeleton, although several questions remain. The major unresolved issue is whether $\mathrm{E}$ acts on the male skeleton mainly to enhance bone mass during growth and maturation, or whether it also acts to retard bone loss in aging individuals. Thus, since the ER- $\alpha$ mutant and aromatase-deficient males had immature skeletons, it is possible that $\mathrm{E}$ primarily plays a role in determining skeletal modeling and the acquisition of peak bone mass, but not in regulating bone turnover (and hence, bone loss) in aging men.

Several cross-sectional observational studies (6-10) have attempted to address this issue by relating bone mineral density (BMD) to sex steroids in elderly men. In these studies, $\mathrm{E}$ (and in particular, the bioavailable or non-sex hormone binding globulin [non-SHBG] bound fraction) did correlate better with BMD than $\mathrm{T}$. However, since both $\mathrm{T}$ and $\mathrm{E}$ levels are correlated with each other (7), these observational data could not conclusively separate the relative contributions of each to skeletal metabolism in elderly men. In addition, since BMD in elderly men is a function both of peak bone mass and bone loss with aging, they also could not dissociate the effects of $E$ on the acquisition of peak bone mass in early adulthood from its effects on continued bone loss later in life.

In addition to its intrinsic importance for our understanding of skeletal physiology, this issue also has significant practical implications. Thus, while men lack the rapid phase of bone loss present at menopause in women, they lose substantial amounts of bone with aging (11-14). In addition, population-based studies have shown that bone resorption increases with age in 
men, and this is accompanied by marked decreases in bioavailable $\mathrm{T}$ and $\mathrm{E}$ levels in elderly men (8). Thus, dissecting out the relative contributions of $T$ versus $E$ in regulating bone turnover, and in particular, bone resorption, in normal elderly men is not only critical to our understanding of the role of sex steroids in the male skeleton, but may also have significant implications for the treatment of male osteoporosis.

In the present study, we addressed this issue directly by eliminating endogenous $\mathrm{T}$ and $\mathrm{E}$ production in normal elderly men and studying them first under conditions of physiologic $\mathrm{T}$ and $\mathrm{E}$ replacement. We then assessed the impact on bone turnover markers of withdrawing both $\mathrm{T}$ and $\mathrm{E}$, continuing both, or withdrawing either $\mathrm{T}$ or $\mathrm{E}$. Using this rigorous, factorial study design, we were thus able to deconvolute the relative contributions of $\mathrm{T}$ versus $\mathrm{E}$ in regulating bone turnover in normal elderly men.

\section{Methods}

Study subjects. After approval of the protocol by the Mayo Institutional Review Board and obtaining written, informed consent, 59 elderly men (age $68.4 \pm 6.1$ years [mean $\pm \mathrm{SD}]$ ) were recruited for the studies. All subjects were interviewed for medical history and underwent a physical examination, including a digital rectal examination for prostatic abnormalities. Subjects were excluded if they were taking any medications known to affect calcium metabolism (i.e., glucocorticoids, anticonvulsants, calcium supplements $>1000$ $\mathrm{mg} / \mathrm{d}$, vitamin $\mathrm{D}>1000 \mathrm{IU} / \mathrm{d}$, sodium fluoride, $\mathrm{T}$ replacement therapy, calcitonin, or bisphosphonates). Other exclusions were subjects who were within six months of a major surgical procedure or traumatic fracture, those with significant medical diseases such as renal failure, malabsorption, active malignancy (including prior history of prostate cancer), or congestive heart failure. Subjects were also excluded if they had a history of a nontraumatic fracture of the vertebrae, hip, or distal forearm. All subjects underwent a screening panel, which included a complete blood count, serum chemistry profile, and a prostate-specific antigen, and any subject with significant abnormalities in any of these parameters was excluded.

Study design. Figure 1 depicts the overall design of the study. Prior to entry into the study, the subjects had a fasting blood sample drawn for measurement of total $\mathrm{T}$ and estradiol $\left(\mathrm{E}_{2}\right)$ levels. At the time of entry into the study, the subjects were administered a long acting GnRH agonist (leuprolide acetate, LupronDepot; Takeda Chemical Industries, Osaka, Japan), $7.5 \mathrm{mg}$ intramuscularly, to suppress endogenous $\mathrm{T}$ and $\mathrm{E}$ production. They were also started on the aromatase inhibitor letrozole (Femara; Novartis, East Hanover, New Jersey, USA), $2.5 \mathrm{mg} / \mathrm{d}$. Physiological T and $\mathrm{E}_{2}$ levels were maintained by starting the subjects on a T patch (Testoderm TTS; Alza Corp., Palo Alto, California, USA), $5 \mathrm{mg} / \mathrm{d}$, as well as an $\mathrm{E}_{2}$ patch (Vivelle; Novartis), $0.0375 \mathrm{mg} / \mathrm{d}$. The doses of the $\mathrm{T}$ and
$E_{2}$ patches were chosen based on the serum levels previously shown to be achieved by these doses, which were similar to physiologic circulating $\mathrm{T}$ and $\mathrm{E}_{2}$ levels in normal men $(15,16)$. After 3 weeks following GnRH agonist administration and while maintaining letrozole, $T$, and $E_{2}$ treatment, the subjects were admitted to the Mayo General Clinical Research Center (GCRC) for their base-line visit (Figure 1). After an overnight fast, serum samples were drawn at 8 am for calcium, phosphorus, albumin, total and bioavailable $\mathrm{T}, \mathrm{E}_{2}$ parathyroid hormone (PTH), osteocalcin, amino-terminal propeptide of type I procollagen (PINP), and bone-specific alkaline phosphatase (BSAP). A second blood sample was drawn at $2 \mathrm{pm}$ for $T$ levels, to ensure adequate absorption of $\mathrm{T}$ from the patches, and the mean of these two values was used. Two consecutive 24-hour urine collections were obtained for measurement of urinary total deoxypyridinoline (Dpd) and $\mathrm{N}$-telopeptide of type I collagen (NTx). On the second day in the GCRC, another set of fasting serum samples was obtained for PTH, osteocalcin, PINP, and BSAP. For the analyses, the mean of the two consecutive measurements of PTH, osteocalcin, PINP, BSAP, and urinary Dpd and NTx were used to try to minimize effects of day to day variability in these parameters.

Following the base-line studies, the subjects were randomized into one of four groups: Group A (-T, -E; $n=14)$ discontinued both $\mathrm{T}$ and $\mathrm{E}$ patches; Group $\mathrm{B}$ $(-\mathrm{T},+\mathrm{E} ; n=15)$ discontinued the $\mathrm{T}$ patch but continued the E patch; Group C (+T, $-\mathrm{E} ; n=15)$ discontinued the $\mathrm{E}$ patch but continued the $\mathrm{T}$ patch; and Group $\mathrm{D}$ $(+\mathrm{T},+\mathrm{E} ; n=15)$ continued both patches. All subjects received a second dose of the GnRH agonist, and all subjects continued letrozole treatment throughout the study period (Figure 1).

Three weeks following randomization, the subjects were readmitted to the GCRC for their final visit. The base-line studies were repeated at this time point, and upon completion of the study, all study medications were discontinued, with the exception that the subjects were placed on the $T$ patch for an additional two weeks to allow the effects of the GnRH agonist to wane (Figure 1). Following the studies, the subjects returned to the GCRC for measurement of total body BMD, fat mass, and lean mass using dual energy X-ray absorptiometry (Lunar DPX-IQ; Lunar Corp., Madison, Wisconsin, USA).

Laboratory methods. Total $\mathrm{T}$ was measured by a competitive chemiluminescent immunoassay on the ACS180 automated immunoassay system (Bayer Diagnostics Corp., Tarrytown, New York, USA; interassay coefficient of variation $(\mathrm{CV})<10 \%$; lower limit of detection, $3 \mathrm{ng} / \mathrm{dl}$ ). $\mathrm{E}_{2}$ was measured by a double antibody radioimmunoassay (Diagnostic Products Corp., Los Angeles, California, USA; interassay CV $<16 \%$; lower limit of detection, $1 \mathrm{pg} / \mathrm{ml}$ ). In addition, the non-SHBG bound (bioavailable) fraction of total $\mathrm{T}$ and $\mathrm{E}_{2}$ was measured using differential precipitation of SHBG by ammonium sulfate, as previously described (8). In brief, 
tracer amounts of $\left[{ }^{3} \mathrm{H}\right]$-labeled $\mathrm{T}$ or $\mathrm{E}_{2}$ were added to serum aliquots. An equal volume of a saturated solution of ammonium sulfate (final concentration, 50\%) was added to precipitate SHBG with its bound steroid. Separation of the SHBG fraction was done by centrifugation at $1100 \mathrm{~g}$ for 30 minutes at $4^{\circ} \mathrm{C}$. The percentage of labeled steroid remaining in the supernatant (the free and albumin-bound fractions) was then calculated. The bioavailable steroid concentration was obtained by multiplying the total steroid concentration, as determined by immunoassay, by the fraction that was non-SHBG bound.

Bone resorption was assessed by measurement of urinary total Dpd and NTx. Total Dpd was measured in hydrolyzed urine after solid-phase extraction by reverse phase high performance liquid chromatography and fluorescent detection with internal standard (interassay $\mathrm{CV}<15 \%$ ), as previously described (17). NTx was measured in Sheffield, United Kingdom by automated luminescence immunoassay analyzer (Vitros Eci; Ortho Clinical Diagnostics, Chalfont St. Giles, United Kingdom; interassay $\mathrm{CV}<4 \%$ ), and the results were expressed as bone collagen equivalents (BCEs). Bone formation was assessed by serum osteocalcin, PINP, and BSAP. Osteocalcin was measured by the ELSA-Osteo two-site immunoradiometric assay (CIS-BIO International, Bedford, Massachusetts, USA; interassay CV < 11\%). PINP was measured by a double antibody radioimmunoassay (Orion Diagnostica, Espoo, Finland; interassay CV < $13 \%)$. BSAP was measured by enzymatic immunoassay (Quidel Corp., San Diego, California, USA; interassay $\mathrm{CV}<10 \%)$. Serum intact PTH was measured by a two site chemiluminescent immunometric assay on the Immulite automated immunoassay system (Diagnostic Products Corp.; interassay CV < 9\%). Serum 25-hydroxyvitamin $\mathrm{D}$ was measured by a competitive proteinbinding assay (Nichols Institute Diagnostics, San Juan Capistrano, California, USA; interassay CV < 15\%). Serum calcium, phosphorus, and albumin were measured by automated analyzer (Hitachi Instruments, Tokyo, Japan), and albumin-corrected calcium calculated as previously described (18).

Statistical analysis. The primary method of analysis to dissect out effects of $E$ versus $T$ on the changes in the bone markers and parameters relating to calcium metabolism took advantage of the factorial design. Thus, we used a two-factor analysis of variance (ANOVA) model to compare the percent changes in these variables in the $+\mathrm{E}$ (Groups $\mathrm{B}$ and $\mathrm{D})$ versus the $-\mathrm{E}$ (Groups A and C) and the + $\mathrm{T}$ (Groups $\mathrm{C}$ and $\mathrm{D}$ ) versus the $-\mathrm{T}$ (Groups A and $\mathrm{C}$ ) groups. This analysis also allowed us to test for any interactions between $\mathrm{E}$ and $\mathrm{T}$ for effects on these variables. A paired $t$-test was used to compare pre-entry to base-line sex steroid levels, and a one-sample $t$-test was used to assess percent change from base line for each variable. Base-line clinical characteristics and values for the bone markers and parameters related to calcium metabolism were compared between groups using a one factor ANOVA model. If

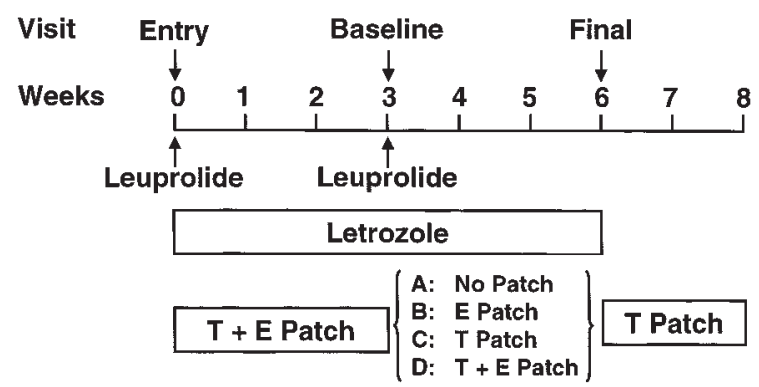

Figure 1

Schematic representation of the study design. Following the base-line visit, the subjects were randomized into one of four groups, as indicated.

the ANOVA was significant, the Tukey method (19) was used for pairwise comparisons. Results were considered significant at the $P<0.05$ level, and the data are reported as the mean \pm SEM.

\section{Results}

Clinical characteristics and body composition. Table 1 shows the clinical characteristics and variables related to body composition in the subjects in the four groups. As evident, the subjects were well matched for anthropomorphic indices, total body BMD and bone mineral content (BMC), as well as fat and lean mass. Despite the randomization, there was a small difference in age across the groups, with the subjects in Group D being slightly younger than the subjects in Group B.

Sex steroid levels. Following entry into the study, we suppressed endogenous $\mathrm{T}$ and $\mathrm{E}$ production in the study subjects and replaced them with exogenous $T$ and $\mathrm{E}_{2}$ for the base-line studies (Figure 1). With our interventions, we were successfully able to mimic endogenous circulating sex steroid levels in these men, since $\mathrm{T}$ and $\mathrm{E}_{2}$ levels at the base-line visit $(422 \pm 21 \mathrm{ng} / \mathrm{dl}$ and 35 $\pm 3 \mathrm{pg} / \mathrm{ml}$, respectively, mean \pm SEM) were very similar to the $T$ and $E_{2}$ levels in these subjects prior to entry into the study $(403 \pm 16 \mathrm{ng} / \mathrm{dl}$ and $31 \pm 1 \mathrm{pg} / \mathrm{ml}, P=0.423$ and 0.128 for comparison between pre-entry and baseline $\mathrm{T}$ and $\mathrm{E}_{2}$ levels, respectively). Moreover, these values were also very similar to those we have previously found in comparable men in the population (8).

Table 2 shows the sex steroid levels in the four groups at the time of the final visit (see Figure 1). As expected, following $\mathrm{T}$ and $\mathrm{E}$ withdrawal, sex steroid levels in Group A fell into the castrate range, whereas they remained essentially unchanged in the subjects in Group D, who continued both patches. The subjects in Group B, in whom the $T$ patch was discontinued, had low $\mathrm{T}$ but normal $\mathrm{E}_{2}$ levels, whereas the subjects in Groups C, in whom the E patch was discontinued, had normal $\mathrm{T}$ but markedly suppressed $\mathrm{E}_{2}$ levels (Table 2).

Bone turnover markers and variables related to calcium metabolism. Table 3 shows the values for the bone turnover markers and variables related to calcium metabolism in the four groups at base line. As evident, 
Table 1

Clinical characteristics and variables related to body composition in the study subjects

\begin{tabular}{lccccc}
\hline & $\begin{array}{c}\text { Group A } \\
(-\mathrm{T},-\mathrm{E})\end{array}$ & $\begin{array}{c}\text { Group B } \\
(-\mathrm{T},+\mathrm{E})\end{array}$ & $\begin{array}{c}\text { Group C } \\
(+\mathrm{T},-\mathrm{E})\end{array}$ & $\begin{array}{c}\text { Group } \mathrm{D} \\
(+\mathrm{T},+\mathrm{E})\end{array}$ & $P$ value \\
$n$ & 14 & 15 & 15 & 15 & \\
Age, years & $69.2 \pm 1.7$ & $71.5 \pm 1.8$ & $67.3 \pm 1.3$ & $65.8 \pm 1.0^{\mathrm{A}}$ & 0.046 \\
Height, $\mathrm{m}$ & $1.75 \pm 0.02$ & $1.75 \pm 0.02$ & $1.75 \pm 0.02$ & $1.76 \pm 0.02$ & 0.963 \\
Weight, $\mathrm{kg}$ & $86.4 \pm 4.1$ & $88.9 \pm 4.2$ & $86.8 \pm 2.7$ & $87.7 \pm 3.3$ & 0.962 \\
Body mass index, $\mathrm{kg} / \mathrm{m}^{2}$ & $28.1 \pm 1.2$ & $29.2 \pm 1.5$ & $28.6 \pm 1.1$ & $28.2 \pm 0.9$ & 0.922 \\
Total body BMD, g/cm² & $1.27 \pm 0.02$ & $1.29 \pm 0.02$ & $1.25 \pm 0.03$ & $1.26 \pm 0.02$ & 0.635 \\
Total body BMC, kg & $3.22 \pm 0.09$ & $3.30 \pm 0.12$ & $3.13 \pm 0.12$ & $3.25 \pm 0.12$ & 0.748 \\
Fat mass, $\mathrm{kg}$ & $24.49 \pm 2.41$ & $25.83 \pm 2.62$ & $25.78 \pm 1.92$ & $25.64 \pm 1.89$ & 0.971 \\
Lean mass, $\mathrm{kg}$ & $56.58 \pm 1.85$ & $57.50 \pm 1.54$ & $56.65 \pm 1.19$ & $57.62 \pm 1.87$ & 0.953 \\
Smokers, $n(\%)$ & $1(7.1)$ & $1(6.7)$ & $1(6.7)$ & $0(0.0)$ & 0.781
\end{tabular}

$P$ value is for comparison across groups by ANOVA. AP $<0.05$ versus Group B.

there were no significant differences noted in any of these parameters between the groups.

Figure 2 depicts the changes in the bone resorption markers, urinary Dpd (top panel) and NTx (bottom panel), between the base-line and final visits in the four groups. As is evident, urinary Dpd excretion increased significantly (by 26\%) in the group that discontinued both patches (Group A) and remained unchanged in the group that continued both patches (Group D). Dpd showed a small (but not significant) increase (of 9\%) in Group B $(-\mathrm{T},+\mathrm{E})$, whereas it increased to a greater extent $(20 \%)$ in Group C $(+\mathrm{T},-\mathrm{E})$. To test more rigorously for independent effects of $\mathrm{T}$ and $\mathrm{E}$ on urinary Dpd excretion, we took advantage of our factorial design by comparing the $+\mathrm{E}(\mathrm{B}$ and $\mathrm{D})$ to the $-\mathrm{E}(\mathrm{A}$ and $\mathrm{C})$ groups and the $+\mathrm{T}(\mathrm{C}$ and $\mathrm{D})$ to the -T (A and B) groups, using the two-factor ANOVA model (see Methods). In this analysis, there was a clear effect of $\mathrm{E}$, but not $\mathrm{T}$, on urinary Dpd excretion $(P=$ 0.005 and 0.232 for $E$ and $T$, respectively). While both $\mathrm{E}$ and $\mathrm{T}$ appeared to be more effective than either alone in preventing the increase in Dpd excretion following sex steroid deficiency (Figure 2, top panel), we could not detect a statistically significant interaction between the two in our ANOVA model $(P=0.675$ for an interaction term), arguing against any synergistic effects of the two on Dpd excretion.

The changes in urinary NTx excretion followed essentially the same pattern as for Dpd (Figure 2, bottom panel). Thus, NTx excretion increased significantly in Group A (-T, -E) (by 35\%), but remained unchanged in Group D $(+\mathrm{T},+\mathrm{E})$. NTx showed a small (9\%), but in this case, significant, increase in Group B

Table 2

\begin{tabular}{lcccc}
\multicolumn{5}{l}{ Sex steroid levels in the study subjects at the time of the final visit } \\
$\begin{array}{l}\text { Group } \mathrm{A} \\
(-\mathrm{T},-\mathrm{E})\end{array}$ & $\begin{array}{c}\text { Group B } \\
(-\mathrm{T},+\mathrm{E})\end{array}$ & $\begin{array}{c}\text { Group C } \\
(+\mathrm{T},-\mathrm{E})\end{array}$ & $\begin{array}{c}\text { Group } \mathrm{D} \\
(+\mathrm{T},+\mathrm{E})\end{array}$ \\
$\mathrm{T}, \mathrm{ng} / \mathrm{dl}$ & $18 \pm 3$ & $19 \pm 2$ & $375 \pm 28$ & $409 \pm 45$ \\
$\mathrm{E}_{2}, \mathrm{pg} / \mathrm{ml}$ & $3 \pm 2$ & $31 \pm 6$ & $6 \pm 5$ & $35 \pm 4$ \\
$\mathrm{Bio}, \mathrm{ng} / \mathrm{dl}$ & $3 \pm 1$ & $3 \pm 1$ & $77 \pm 8$ & $85 \pm 16$ \\
$\mathrm{Bio} \mathrm{E}_{2}, \mathrm{pg} / \mathrm{ml}$ & $1 \pm 1$ & $9 \pm 2$ & $2 \pm 2$ & $13 \pm 2$
\end{tabular}

See Figure 1 for outline of the study design.
$(-\mathrm{T},+\mathrm{E})$ and, as for Dpd, a larger increase in Group C (+T, -E) (22\%). Again, using the two-factor ANOVA model, we found a highly significant effect of $\mathrm{E}(P=0.0002)$, but a nonsignificant effect of $\mathrm{T}(P$ $=0.085)$ on urinary NTx excretion. As for Dpd, while both $\mathrm{E}$ and $\mathrm{T}$ appeared to be more effective than either alone (Figure 2, bottom panel), the interaction term in the ANOVA model was not significant $(P=0.737)$. Taken together, therefore, the data with Dpd and NTx indicate that $\mathrm{E}$ clearly exerted the dominant effect on bone resorption in normal elderly men, and while there may have been a small effect of $\mathrm{T}$, it was not statistically significant in this analysis.

Figure 3 depicts the changes in the bone formation markers, serum osteocalcin (top panel) and PINP (bottom panel), in the four groups. Serum osteocalcin levels decreased significantly $(16 \%)$ in Group A $(-T,-E)$, and did not change in Group D $(+\mathrm{T},+\mathrm{E})$. Of note, serum osteocalcin levels also did not change significantly in either Group B $(-\mathrm{T},+\mathrm{E})$ or Group C $(+\mathrm{T},-\mathrm{E})$. Using the ANOVA model, we found that both $\mathrm{E}$ and $\mathrm{T}$ had significant effects in maintaining serum osteocalcin levels in

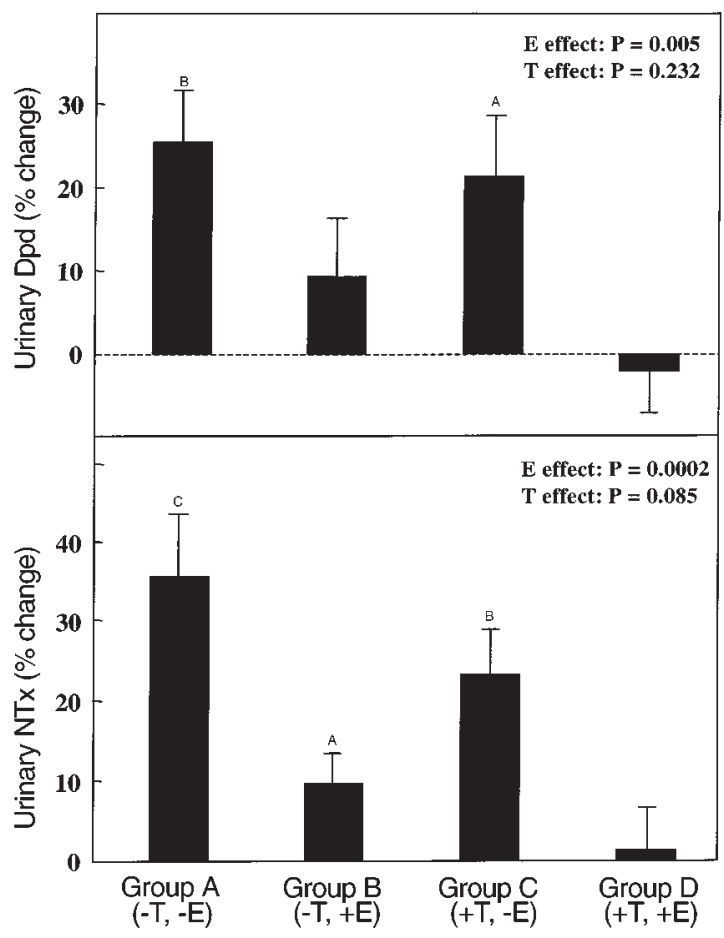

Figure 2

Changes in urinary Dpd (top panel) and NTx (bottom panel) excretion in the four groups between the base-line and final visits. ${ }^{A} P<$ $0.05,{ }^{B} P<0.005$, and ${ }^{C} P<0.001$ for change from base line. The overall effect of $E$ and $T$ on the bone markers was analyzed using the twofactor ANOVA model described in Methods. 
Table 3

Bone turnover markers and variables related to calcium metabolism in the four groups at base line

\begin{tabular}{|c|c|c|c|c|c|}
\hline & $\begin{array}{c}\text { Group A } \\
(-\mathrm{T},-\mathrm{E})\end{array}$ & $\begin{array}{l}\text { Group B } \\
(-T,+E)\end{array}$ & $\begin{array}{l}\text { Group C } \\
(+T,-E)\end{array}$ & $\begin{array}{l}\text { Group D } \\
(+T,+E)\end{array}$ & $\begin{array}{c}P \\
\text { value }\end{array}$ \\
\hline \multicolumn{6}{|l|}{ Bone resorption markers } \\
\hline $\begin{array}{l}\text { Dpd, nmol/d } \\
\text { NTx, nmol BCE/d }\end{array}$ & $\begin{array}{l}172 \pm 14 \\
495 \pm 38\end{array}$ & $\begin{array}{l}156 \pm 13 \\
506 \pm 64\end{array}$ & $\begin{array}{l}169 \pm 19 \\
494 \pm 84\end{array}$ & $\begin{array}{l}164 \pm 12 \\
480 \pm 51\end{array}$ & $\begin{array}{l}0.880 \\
0.993\end{array}$ \\
\hline \multicolumn{6}{|l|}{ Bone formation markers } \\
\hline $\begin{array}{l}\mathrm{OC}, \mathrm{ng} / \mathrm{ml} \\
\mathrm{PINP}, \mu \mathrm{g} / \mathrm{I} \\
\mathrm{BSAP}, \mathrm{U} / \mathrm{I}\end{array}$ & $\begin{array}{l}23.8 \pm 1.7 \\
39.7 \pm 3.6 \\
18.6 \pm 1.6\end{array}$ & $\begin{array}{l}23.3 \pm 2.9 \\
40.6 \pm 5.8 \\
16.9 \pm 1.2\end{array}$ & $\begin{array}{l}21.6 \pm 2.1 \\
39.7 \pm 5.1 \\
18.1 \pm 1.9\end{array}$ & $\begin{array}{r}21.3 \pm 1.9 \\
38.6 \pm 4.6 \\
17.1 \pm 1.2\end{array}$ & $\begin{array}{l}0.809 \\
0.994 \\
0.839\end{array}$ \\
\hline Calcium, mg/dl & $8.8 \pm 0.1$ & $9.0 \pm 0.1$ & $9.0 \pm 0.1$ & $8.9 \pm 0.1$ & 0.265 \\
\hline Albumin-corrected calcium, mg/dl & $9.2 \pm 0.1$ & $9.2 \pm 0.1$ & $9.1 \pm 0.1$ & $9.1 \pm 0.1$ & 0.33 \\
\hline Phosphorus, mg/dl & $3.0 \pm 0.1$ & $3.0 \pm 0.1$ & $3.0 \pm 0.1$ & $2.9 \pm 0.1$ & 0.95 \\
\hline PTH, pmol/l & $5.1 \pm 0.6$ & $5.2 \pm 0.5$ & $4.1 \pm 0.4$ & $4.6 \pm 0.4$ & 0.31 \\
\hline $25-(\mathrm{OH}) \mathrm{D}, \mathrm{ng} / \mathrm{ml}$ & $32.9 \pm 2.0$ & $30.4 \pm 2.1$ & $29.2 \pm 2.1$ & $34.1 \pm 2.7$ & 0.39 \\
\hline
\end{tabular}

$P$ value is for comparison across groups by ANOVA. OC, osteocalcin; $25-(\mathrm{OH}) \mathrm{D}, 25$-hydroxyvitamin $\mathrm{D}$.

also in group $\mathrm{C}(+\mathrm{T},-\mathrm{E})$. However, despite no change in serum $\mathrm{PTH}$ levels in Group B $(-T,+E)$, serum phosphorus did increase significantly in these subjects, and by the ANOVA model, both $\mathrm{E}$ and $\mathrm{T}$ had significant effects on the changes in serum phosphorus levels.

\section{Discussion}

Although data from the ER- $\alpha$ negative male (1), the aromatase deficient males (2-4) and crosssectional observational studies (6-10) demonstrate that E plays a role in the acquisition and maintenance of $\mathrm{BMD}$, whether $\mathrm{E}$ also effects bone loss in men is unclear. However, our study clearly establishes that $\mathrm{E}$ regulates

these men $(P=0.002$ and 0.013 for $\mathrm{E}$ and $\mathrm{T}$, respectively). As with the resorption markers, $E$ and $T$ appeared to have additive effects on serum osteocalcin levels (Figure 3 , top panel), but again, the interaction term in the ANOVA model was not significant $(P=0.963)$.

Similar to the findings with osteocalcin, serum PINP levels fell significantly $(22 \%)$ in Group A $(-\mathrm{T},-\mathrm{E})$, and did not change in Group D $(+\mathrm{T},+\mathrm{E})$ (Figure 3, bottom panel). Also similar to osteocalcin, PINP levels did not change in Group B $(-\mathrm{T},+\mathrm{E})$, but in contrast to the osteocalcin data, serum PINP levels did decrease significantly (16\%) in Group C (+T, -E). Using the ANOVA model, we found a significant $\mathrm{E}$ effect $(P=0.0001)$, but no T effect $(P=0.452)$ on PINP levels.

Serum BSAP did not change significantly over the three-week time period in the group made hypogonadal (Group A), or in Groups B $(-\mathrm{T},+\mathrm{E})$ and $\mathrm{D}(+\mathrm{T}$, $+\mathrm{E}$ ) (changes of $-0.2 \pm 2.9 \%, 4.9 \pm 3.0 \%$, and $-1.9 \pm$ $1.7 \%$, respectively [mean \pm SEM] $)$, although there was a slight decrease in Group C (+T, - E) $(-6.5 \pm 2.2 \%, P<$ 0.02 versus base line).

Table 4 shows the changes in serum calcium, phosphorus, and PTH levels over the three-week study period in the various groups. There was a small, but statistically significant, increase in serum calcium levels in Groups A $(-\mathrm{T},-\mathrm{E})$ and $\mathrm{C}(+\mathrm{T},-\mathrm{E})$, likely reflecting increased calcium flux from the skeleton as a result of the increase in bone resorption in these groups, whereas serum calcium levels did not change in the E-treated groups (Groups B and D). By the ANOVA model, there was a significant $E$ effect, but no $T$ effect, on changes in serum calcium levels. Serum albumin-corrected calcium showed identical changes (data not shown). The increase in serum calcium levels, in turn, led to a significant decrease in serum PTH levels in the subjects in Group A $(-\mathrm{T},-\mathrm{E})$, and a trend for a decrease in the subjects in Group C $(+\mathrm{T},-\mathrm{E})$. The decrease in serum PTH levels was accompanied by an increase in serum phosphorus levels in Group A (-T, -E) and, to a lesser extent, both bone formation and resorption in normal elderly men in a direction that would oppose bone loss. By directly manipulating $\mathrm{T}$ and $\mathrm{E}$ levels and assessing the changes in bone turnover markers, these data thus provide unequivocal proof of the key role that E plays in skeletal metabolism in men.

While we found that $\mathrm{E}$ was the dominant sex steroid regulating bone resorption in elderly men, $\mathrm{T}$ may make

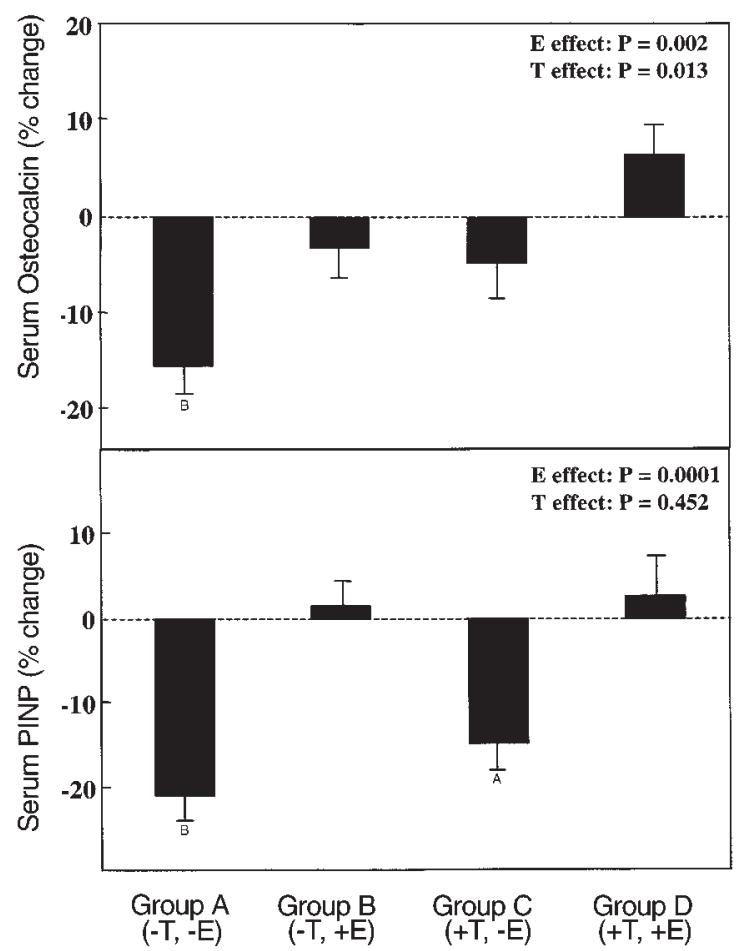

Figure 3

Changes in serum osteocalcin (top panel) and PINP (bottom panel) levels in the four groups between the base-line and final visits. ${ }^{A} P<$ 0.005 and ${ }^{B} P<0.001$ for change from base line. The overall effect of $\mathrm{E}$ and $\mathrm{T}$ on the bone markers was analyzed using the two-factor ANOVA model described in Methods. 
Table 4

Percent changes in serum calcium, phosphorus, and PTH levels in the four groups between the base-line and final visits

\begin{tabular}{lcccccc}
\hline $\begin{array}{c}\text { Group A } \\
(-\mathrm{T},-\mathrm{E})\end{array}$ & $\begin{array}{c}\text { Group B } \\
(-\mathrm{T},+\mathrm{E})\end{array}$ & $\begin{array}{c}\text { Group C } \\
(+\mathrm{T},-\mathrm{E})\end{array}$ & $\begin{array}{c}\text { Group D } \\
(+\mathrm{T},+\mathrm{E})\end{array}$ & E effect & T effect \\
Calcium & $+2.9 \pm 0.9^{\mathrm{B}}$ & $-0.9 \pm 0.5$ & $+1.9 \pm 0.6^{\mathrm{A}}$ & $+0.7 \pm 0.8$ & 0.001 & 0.593 \\
Phosphorus & $+21.3 \pm 2.6^{\mathrm{C}}$ & $+8.5 \pm 1.5^{\mathrm{C}}$ & $+12.2 \pm 3.0^{\mathrm{B}}$ & $+2.9 \pm 2.2$ & 0.0001 & 0.004 \\
PTH & $-13.1 \pm 3.7^{\mathrm{B}}$ & $-0.8 \pm 6.3$ & $-6.2 \pm 6.2$ & $+2.3 \pm 6.1$ & 0.076 & 0.406
\end{tabular}

The overall effect of $E$ and $T$ on these variables was analyzed using the two-factor ANOVA model described in Methods. ${ }^{A} P<0.05,{ }^{B} P<0.01$, and ${ }^{C} P<0.001$ versus base line.

a smaller contribution to the regulation of bone resorption that we lacked the statistical power to detect. Thus, the change in bone resorption markers in Group C $(+\mathrm{T}$, $-\mathrm{E})$ was somewhat less than in Group A $(-\mathrm{T},-\mathrm{E})$, and there was a small increase in the resorption markers in Group B $(-\mathrm{T},+\mathrm{E})$ (Figure 2). Indeed, based on the data in Figure 2, E may have prevented (averaging the data for urinary Dpd and NTx) approximately $70 \%$ of the increase in bone resorption seen in the $\mathrm{T}$ and $\mathrm{E}$ deficient men, whereas $\mathrm{T}$ may have accounted for at most $30 \%$ of the effect. It would, in fact, be surprising if $\mathrm{T}$ had no effect on bone resorption, since in vitro studies have shown that androgens directly inhibit the activity of isolated osteoclasts (20). Moreover, androgens have also been shown to inhibit the production of IL-6, a known proresorptive cytokine, in bone marrow stromal (21) and in mature osteoblastic cells (22).

Our data also demonstrate an effect of both $\mathrm{E}$ and $\mathrm{T}$ on bone formation. Thus, serum osteocalcin levels decreased significantly in the men made hypogonadal, consistent with an important effect of sex steroids in maintaining bone formation in normal men. Since osteocalcin is produced primarily by mature osteoblastic cells and osteocytes (23), the decrease in serum osteocalcin levels we observed in the setting of acute sex steroid deficiency likely reflects apoptosis of these cells, as has previously been shown to occur histologically with GnRH therapy in young women (24). Since both $\mathrm{E}$ and $\mathrm{T}$ were equally effective in preventing this acute decrease in serum osteocalcin levels, our findings indicate an important role for both sex steroids in maintaining bone formation in normal men. These findings are also consistent with recent in vitro observations demonstrating that both $\mathrm{E}$ and $\mathrm{T}$ have antiapoptotic effects on mature osteoblastic cells $(25,26)$.

In contrast to osteocalcin, type I collagen is made by cells in the entire osteoblastic lineage, from the osteoprogenitor to the mature osteoblast (27). Thus, alterations in PINP levels likely reflect changes in multiple stages of osteoblast development, and our data would suggest that it is primarily $\mathrm{E}$, and not $\mathrm{T}$, that regulates this process. Finally, serum BSAP levels did not change significantly following acute sex steroid withdrawal, perhaps reflecting both the relatively long half-life of this marker in serum (28) as well as the fact that, like type I collagen, it is produced by cells at various stages of osteoblast development (27).
The acute decrease in bone formation (over three weeks) in our study mirrors previous observations of an acute increase in bone formation following parenteral administration of $E_{2}$ in postmenopausal women (29). These short-term changes need to be distinguished from the more chronic (over months) changes in bone formation with sex steroid replacement or deficiency. Thus, in contrast to the decrease in serum osteocalcin and PINP levels that we observed following acute sex steroid withdrawal, bone formation markers clearly increase over longer periods of time following gonadectomy in women (30) and in men (31). The most likely explanation for this difference is that the decrease in the bone formation markers in the present study reflects acute effects of sex steroid deficiency on reducing osteoblast number and/or function, whereas the more chronic increase in bone formation with sex steroid deficiency is due to a stimulation of the bone remodeling cycle (32), which results in an increase in bone formation coupled to the increase in bone resorption.

We found that the subjects in Group A $(-\mathrm{T},-\mathrm{E})$ had a significant decrease in serum PTH levels following the induction of hypogonadism. The most plausible explanation for this is that sex steroid deficiency resulted directly in a stimulation of bone resorption, with a consequent flux of calcium from the skeleton. This, in turn, resulted in a suppression of PTH secretion, as has previously been shown to occur in early postmenopausal women following either a natural menopause or oophorectomy (33-36). Consistent with this, there was a small, but statistically significant, increase in serum calcium levels that accompanied the increase in bone resorption markers in the subjects in Group A. While the precise mechanism(s) of the direct effects of sex steroids on the skeleton has not been defined, it appears likely that sex steroid deficiency results in upregulation in the bone microenvironment of a number of cytokines that stimulate bone resorption, downregulation of antiresorptive factors such as transforming growth factor- $\beta$ or the decoy receptor for RANK-L, osteoprotegerin (for reviews, see refs. 37, 38), and/or decreased osteoclast apoptosis (39). These decreases in serum PTH following acute sex steroid deficiency are to be distinguished from the proposed development of secondary hyperparathyroidism in the setting of chronic (i.e., over years) sex steroid deficiency (36), which likely results from a loss of the extraskeletal actions of $\mathrm{E}$ (and possibly $\mathrm{T}$ ) on intestinal calcium absorption $(40,41)$ and renal calcium handling $(34,42)$.

Our findings in men demonstrating an important role for $\mathrm{E}$ in regulating bone resorption and formation are consistent with data showing significant effects of $E$ on bone metabolism in male rodents. Thus, Vanderschueren et al. (43) found that either orchidectomy or the aromatase inhibitor vorazole, induced a similar reduction in BMD of the femur and lumbar vertebrae in 
male rats. In addition, ER- $\alpha$ knockout (44) and aromatase knockout (45) male mice have significant reductions in bone mass, although for reasons that remain unclear, the findings in the rodent knockout models are much less striking than in the human mutant males. Finally, Erben et al. (46) have recently reported that orchidectomy in aged male rats induced high turnover osteopenia, and using multiple regression models, $\mathrm{E}_{2}$ (but not $\mathrm{T}$ ) was a significant predictor of bone turnover in both the sham and orchidectomized rats.

As in our study in humans, however, animal studies have also shown clear effects of androgens on bone, even in the absence of aromatization to estrogens. Thus, Vanderschueren et al. (47) found that aromatizable and nonaromatizable androgens were effective in preventing bone loss in aged male rats following orchiectomy, and several studies have found that androgens attenuated or prevented bone loss following ovariectomy in female rats $(42,48-50)$. Moreover, both rats (51) and humans (52-54) with testicular feminization have been reported to have deficits in BMD, reflecting an important role of androgens in the development of the skeleton. Indeed, Turner et al. (55) have shown that androgens stimulate periosteal bone formation in rats, and this may, in part, be responsible for the obvious sexual dimorphism of the skeleton that develops at the time of puberty, with males having larger bones with thicker cortices (56).

Our findings may also have significant implications for our understanding of age-related bone loss in men. Thus, we have previously reported that bone resorption increases with age in a population-based sample of men (8), and if bone formation is unable to adequately compensate for the increase in bone resorption, bone loss will ensue. Our data indicate that sex steroid deficiency in men is associated both with increased bone resorption markers and suppressed bone formation markers and thus can cause both defects associated with bone loss in elderly men. We have previously shown that both bioavailable $\mathrm{T}$ and $\mathrm{E}$ levels decline markedly with age in men (8). Although E appears to be the dominant sex steroid controlling bone resorption and formation, $T$ may also contribute to the net effect of sex steroids on bone, and T deficiency in elderly men may also indirectly effect skeletal metabolism by limiting the substrate available for aromatization to E. Thus, a plausible hypothesis is that the declining bioavailable $\mathrm{E}$ and $\mathrm{T}$ levels are responsible, at least in part, for the age-related increase in bone resorption, impaired compensatory bone formation, and bone loss in elderly men. Clearly, further studies are needed to more directly address this issue.

These data also suggest that elderly men with low bioavailable E levels might benefit from either low dose E replacement or from the use of selective estrogen receptor modulators (SERMs) that have an agonist effect on the skeleton but are not feminizing. Indeed, in a preliminary study, Taxel et al. (57) treated nine elderly men with either $0.5 \mathrm{mg}$ or $2.0 \mathrm{mg}$ daily of micronized $17 \beta-E_{2}$ and found significant reductions in bone resorption markers. In addition, Anderson et al. (58) treated 21 eugonadal men with osteoporosis with intramuscular $\mathrm{T}$ and found a significant increase in lumbar spine BMD, which was correlated with changes in serum $\mathrm{E}_{2}$, but not $\mathrm{T}$ levels. Finally, our findings would suggest that SERMs might have clinical utility in at least the subset of elderly men with low bioavailable E levels.

In summary, our findings clearly establish that $\mathrm{E}$ is the dominant sex steroid regulating bone resorption in normal elderly men. Moreover, both $\mathrm{E}$ and $\mathrm{T}$ appear to play major roles in maintaining bone formation in vivo, perhaps through effects on inhibiting osteoblast apoptosis. These findings have important implications not only for our understanding of skeletal metabolism in men, but also in terms of the potential mechanism(s) of age-related bone loss in men as well as approaches to prevent or treat osteoporosis in men.

\section{Acknowledgments}

We would like to thank our study volunteers, the staff of the GCRC, Roberta Soderberg (for processing the samples), Sara Achenbach (for help with the statistical analyses), and R.A. Hannon (for performing the NTx assays). This work was supported by grants AG-04875 from the National Institute on Aging and RR-00585 from the NIH.

1. Smith, E.P., et al. 1994. Estrogen resistance caused by a mutation in the estrogen-receptor gene in a man. N. Engl. J. Med. 331:1056-1061.

2. Morishima, A., Grumbach, M.M., Simpson, E.R., Fisher, C., and Qin, K. 1995. Aromatase deficiency in male and female siblings caused by a novel mutation and the physiological role of estrogens. J. Clin. Endocrinol. Metab. 80:3689-3698.

3. Carani, C., et al. 1997. Effect of testosterone and estradiol in a man with aromatase deficiency. N. Engl. J. Med. 337:91-95.

4. Bilezikian, J.P., Morishima, A., Bell, J., and Grumbach, M.M. 1998. Increased bone mass as a result of estrogen therapy in a man with aromatase deficiency. N. Engl. J. Med. 339:599-603.

5. Rochira, V., Faustini-Fustini, M., Balestrieri, A., and Carani, C. 2000. Estrogen replacement therapy in a man with congenital aromatase deficiency: effects of different doses of transdermal estradiol on bone mineral density and hormonal parameters. J. Clin. Endocrinol. Metab. 85:1841-1845.

6. Slemenda, C.W., et al. 1997. Sex steroids and bone mass in older men: positive associations with serum estrogens and negative associations with androgens. J. Clin. Invest. 100:1755-1759.

7. Greendale, G.A., Edelstein, S., and Barrett-Connor, E. 1997. Endogenous sex steroids and bone mineral density in older women and men: the Rancho Bernardo Study. J. Bone Miner. Res. 12:1833-1843.

8. Khosla, S., et al. 1998. Relationship of serum sex steroid levels and bone turnover markers with bone mineral density in men and women: a key role for bioavailable estrogen. J. Clin. Endocrinol. Metab. 83:2266-2274.

9. Ongphiphadhanakul, B., Rajatanavin, R., Chanprasertyothin, S., Piaseu, N., and Chailurkit, L. 1998. Serum oestradiol and oestrogen-receptor gene polymorphism are associated with bone mineral density independently of serum testosterone in normal males. Clin. Endocrinol. 49:803-809.

10. Center, J.R., Nguyen, T.V., Sambrook, P.N., and Eisman, J.A. 1999. Hormonal and biochemical parameters in the determination of osteoporosis in elderly men. J. Clin. Endocrinol. Metab. 84:3626-3635.

11. Meier, D.E., Orwoll, E.S., and Jones, J.M. 1984. Marked disparity between trabecular and cortical bone loss with age in healthy men. Measurement by vertebral computed tomography and radial photon absorptiometry. Ann. Intern. Med. 101:605-612.

12. Jones, G.T., Nguyen, V., Sambrook, P.N., Kelly, P.J., and Eisman, J.A. 1994. Progressive loss of bone in the femoral neck in elderly people: longitudinal findings from the Dubbo Osteoporosis Epidemiology Study. $\mathrm{Br}$. Med. J. 309:691-695.

13. Fatayerji, D., Cooper, A.M., and Eastell, R. 1999. Total and regional bone 
mineral density in men: effect of age. Osteoporosis Int. 10:59-65.

14. Melton, L.J., III, et al. 2000. Cross-sectional versus longitudinal evaluation of bone loss in men and women. Osteoporosis Int. 11:592-599.

15. Testoderm TTS. Testosterone transdermal system. 2000. In Physicians desk reference. Medical Economics Co. Montvale, New Jersey, USA. 515-518.

16. Vivelle. Estradiol transdermal system. 2000. In Physicians' desk reference. Medical Economics Co. Montvale, New Jersey, USA. 2055-2058.

17. Black, D., Duncan, A., and Robins, S.P. 1988. Quantitative analysis of the pyridinium crosslinks of collagen in urine using ion-paired reversedphase high-performance liquid chromatography. Anal. Biochem. 169:197-203.

18. Thode, J., et al. 1989. Comparison of serum total calcium, albumin-corrected total calcium, and ionized calcium in 1213 patients with suspected calcium disorders. Scand. J. Clin. Lab. Invest. 49:217-223.

19. The GLM procedure. 1990. In SAS/STAT user's guide. Sixth edition. SAS Institute Inc. Cary, North Carolina, USA. 891-996.

20. Pederson, L., et al. 1999. Androgens regulate bone resorption activity of isolated osteoclasts in vitro. Proc. Natl. Acad. Sci. USA. 96:505-510.

21. Bellido, T., et al. 1995. Regulation of interleukin-6, osteoclastogenesis, and bone mass by androgens. J. Clin. Invest. 95:2886-2895.

22. Hofbauer, L.C., Ten, R.M., and Khosla, S. 1999. The anti-androgen hydroxyflutamide and androgens inhibit interleukin- 6 production by an androgen-responsive human osteoblastic cell line. J. Bone Miner. Res. 14:1330-1337.

23. Kasai, R., Bianco, P., Gehron Robey, P., and Kahn, A.J. 1994. Production and characterization of an antibody against the human bone GLA protein (BGP/osteocalcin) propeptide and its use in immunocytochemistry of bone cells. Bone Miner. 25:167-182.

24. Tomkinson, A., Reeve, J., Shaw, R.W., and Noble, B.S. 1997. The death of osteocytes via apoptosis accompanies estrogen withdrawal in human bone. J. Clin. Endocrinol. Metab. 82:3128-3135.

25. Weinstein, R., et al. 1999. Like estrogen, androgens exert potent and direct anti-apoptotic effects on osteoblasts and osteocytes in vivo and in vitro. J. Bone Miner. Res. 14(Suppl. 1):S451. (Abstr.)

26. Manolagas, S.C. 2000. Birth and death of bone cells: basic regulatory mechanisms and implications for the pathogenesis and treatment of osteoporosis. Endocr. Rev. 21:115-137.

27. Lian, J.B., Stein, G.S., Canalis, E., Gehron Robey, P., and Boskey, A.L. 1999. Bone formation: osteoblast lineage cells, growth factors, matrix proteins, and the mineralization process. In Primer on the metabolic bone diseases and disorders of mineral metabolism. 4th edition. M.F. Favus, editor. Lippincott Williams and Wilkins. Philadelphia, Pennsylvania, USA. 14-38.

28. Posen, S., and Grundstein, H.S. 1982. Turnover rate of skeletal alkaline phosphatase in humans. Clin. Chem. 28:153-154

29. Hannon, R., Blumsohn, A., Naylor, K., and Eastell, R. 1998. Response of biochemical markers of bone turnover to hormone replacement therapy: impact of biological variability. J. Bone Miner. Res. 13:1124-1133.

30. Field, C.S., et al. 1993. Preventive effects of transdermal 17beta-estradiol on osteoporotic changes after surgical menopause: a 2-year placebocontrolled trial. Am. J. Obstet. Gynecol. 168:114-121.

31. Stepan, J.J., Lachman, M., Zverina, J., Pacovsky, V., and Baylink, D.J. 1989. Castrated men exhibit bone loss. Effect of calcitonin treatment on biochemical indices of bone remodeling. J. Clin. Endocrinol. Metab. 69:523-527.

32. Heaney, R.P., Recker, R.R., and Saville, P.D. 1978. Menopausal changes in bone remodeling. J. Lab. Clin. Med. 92:964-970.

33. Pioli, G., et al. 1992. Spontaneous release of interleukin-1 and interleukin- 6 by peripheral blood mononuclear cells after oophorectomy. Clin. Sci. 83:503-507.

34. McKane, W.R., et al. 1995. Mechanism of renal calcium conservation with estrogen replacement therapy in early postmenopausal women: a clinical research center study. J. Clin. Endocrinol. Metab. 80:3458-3464.

35. Zofkova, I., and Kancheva, R.L. 1996. Effect of estrogen status on bone regulating hormones. Bone. 19:227-232.

36. Riggs, B.L., Khosla, S., and Melton, L.J., III. 1998. A unitary model for involutional osteoporosis: estrogen deficiency causes both type I and type II osteoporosis in postmenopausal women and contributes to bone loss in aging men. J. Bone Miner. Res. 13:763-773.

37. Spelsberg, T.C., Subramaniam, M., Riggs, B.L., and Khosla, S. 1999. The actions and interactions of sex steroids and growth factors/cytokines on the skeleton. Mol. Endocrinol. 13:819-828.

38. Pacifici, R. 1996. Estrogen, cytokines, and pathogenesis of postmenopausal osteoporosis. J. Bone Miner. Res. 11:1043-1051.

39. Hughes, D.E., et al. 1996. Estrogen promotes apoptosis of murine osteoclasts mediated by TGF- $\beta$. Nat. Med. 2:1132-1136.

40. Gennari, C., Agnusdei, D., Nardi, P., and Civitelli, R. 1990. Estrogen preserves a normal intestinal responsiveness to 1,25 -dihydroxyvitamin $\mathrm{D}_{3}$ in oophorectomized women. J. Clin. Endocrinol. Metab. 71:1288-1293.

41. Hope, W.G., Ibarra, M.J., and Thomas, M.L. 1992. Testosterone alters duodenal calcium transport and longitudinal bone growth rate in parallel in the male rat. Proc. Soc. Exp. Biol. Med. 200:536-541.

42. Mason, R.A., and Morris, H.A. 1997. Effects of dihydrotestosterone on bone biochemical markers in sham and oophorectomized rats. J. Bone Miner. Res. 12:1431-1437.

43. Vanderschueren, D., Van Herck, E., De Coster, R., and Bouillon, R. 1996. Aromatization of androgens is important for skeletal maintenance of aged male rats. Calcif. Tissue Int. 59:179-183.

44. Korach, K.S., et al. 1996. Estrogen receptor gene disruption: molecular characterization and experimental and clinical phenotypes. Recent Prog. Horm. Res. 51:159-188.

45. Oz, O.K., et al. 2000. Bone has a sexually dimorphic response to aromatase deficiency. J. Bone Miner. Res. 15:507-514.

46. Erben, R.G., Eberle, J., Stahr, K., and Goldberg, M. 2000. Androgen deficiency induces high turnover osteopenia in aged male rats: a sequential histomorphometric study. J. Bone Miner. Res. 15:1085-1098.

47. Vanderschueren, D., et al. 1992. Bone and mineral metabolism in aged male rats: short and long term effects of androgen deficiency. Endocrinology. 130:2906-2916

48. Tobias, J.H., Gallagher, A., and Chambers, T.J. 1994. 5 alpha-dihydrotestosterone partially restores cancellous bone volume in osteopenic ovariectomized rats. Am. J. Physiol. 267:E853-E859.

49. Coxam, V., et al. 1996. Effects of dihydrotestosterone alone and combined with estrogen on bone mineral density, bone growth, and formation rates in ovariectomized rats. Bone. 19:107-114.

50. Lea, C.K., and Flanagan, A.M. 1999. Ovarian androgens protect against bone loss in rats made oestrogen deficient by treatment with ICI 182,780. J. Endocrinol. 160:111-117.

51. Vanderschueren, D., et al. 1993. Bone and mineral metabolism in the androgen-resistant (testicular feminized) male rat. J. Bone Miner. Res. 8:801-809.

52. Soule, S.G., et al. 1995. Osteopenia as a feature of the androgen insensitivity syndrome. Clin. Endocrinol. 43:671-675.

53. Bertelloni, S., et al. 1998. Altered bone mineral density in patients with complete androgen insensitivity syndrome. Horm. Res. 50:309-314.

54. Marcus, R., et al. 2000. The contribution of testosterone to skeletal development and maintenance: lessons from the androgen insensitivity syndrome. J. Clin. Endocrinol. Metab. 85:1032-1037.

55. Turner, R.T., Wakley, G.K., and Hannon, K.S. 1990. Differential effects of androgens on cortical bone histomorphometry in gonadectomized male and female rats. J. Orthop. Res. 8:612-617.

56. Fehily, A.M., Coles, R.J., Evans, W.D., and Elwood, P.C. 1992. Factors affecting bone density in young adults. Am. J. Clin. Nutr. 56:579-586.

57. Taxel, P., and Raisz, L.G. 1997. The effect of estrogen therapy on older men with low bone mass. J. Bone Miner. Res, 12(Suppl. 1):S353. (Abstr.)

58. Anderson, F.H., Francis, R.M., Peaston, R.T., and Wastell, H.J. 1997. Androgen supplementation in eugonadal men with osteoporosis: effects of six months' treatment on markers of bone formation and resorption. J. Bone Miner. Res. 12:472-478. 